\title{
Commentary Identification of signaling pathways in early mammary gland development by mouse genetics
}

\section{Gertraud W Robinson}

\author{
Laboratory of Genetics and Physiology, National Institute of Diabetes, and Digestive and Kidney Diseases, National Institutes of Health, Bethesda, \\ Maryland, USA \\ Corresponding author: Gertraud Robinson (e-mail: traudl@nih.gov)
}

Published: 9 March 2004

Breast Cancer Res 2004, 6:105-108 (DOI 10.1186/bcr776)

\begin{abstract}
The mammary gland develops as an appendage of the ectoderm. The prenatal stage of mammary development is hormone independent and is regulated by sequential and reciprocal signaling between the epithelium and the mesenchyme. A number of recent studies using human and mouse genetics, in particular targeted gene deletion and transgenic expression, have identified some of the signals that control specific steps in development. This process involves cell specification and proliferation, reciprocal tissue interactions and cell migration. Since some of these events are recapitulated during tumorigenesis, an understanding of these signaling pathways may contribute to the development of targeted therapies and novel drugs.
\end{abstract}

Keywords: ectodysplasin, fibroblast growth factor, parathyroid hormone-related protein, Tbx3, tissue interaction, wnt

\section{Introduction}

Compared with the numerous investigations performed in the context of postnatal mammary gland development and carcinogenesis, studies of the early stages of mammary gland development are much scarcer. Yet several papers have been published in recent years that shed light on this phase. I shall review our current state of knowledge of the signals that regulate early mammary organogenesis.

\section{Morphology of early mammary development}

Mammary gland development is initiated during embryonic life. The first manifestation of the gland in many mammals is an elevated ridge or milk line, which then fragments into individual buds in specific regions lateral of the dorsal midline. These buds are either located in the thoracic region in primates, in the inguinal area in ungulates or along the entire length of the trunk in rodents and pigs.

In the mouse embryo the first morphological signs of mammary rudiments are lens-like placodes that form around embryonic day 11 and protrude slightly from the body wall. Within 1 day these placodes grow into bulbshaped buds that invaginate the underlying dermis.
Interestingly, growth of the buds is mainly achieved through cell migration from the epidermis. Rapid cell proliferation sets in on embryonic day 15 at the tip of the buds and leads to outgrowth of a primary sprout, which starts to elongate and bifurcate. These processes create a small ductal tree at birth that is connected to the skin and the outside through the nipple. This structure continues to grow at the same pace as the animal until puberty, when hormone-dependent development and rapid ductal elongation and side branching begin.

The surrounding mesenchyme participates in and is also altered in these processes. As soon as the epithelial bud forms, concentric layers of mesenchymal cells orient themselves like a dense halo around the epithelium. These so-called 'mammary mesenchyme' cells are induced by signals coming from the epithelial cells. When the primary sprout elongates, it pushes through this sheath of cells and grows into deeper layers of the dermis toward the presumptive fat pad, which forms the stroma of the adult organ. The mammary mesenchyme remains close to the epidermis and participates in the formation of the nipple (for an in-depth review of these events, see [1]) (Fig. 1a). 
Figure 1

(a)

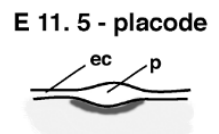

(b)
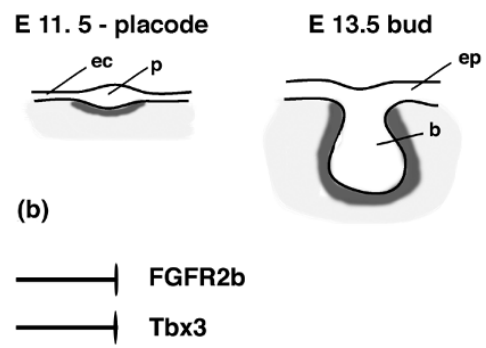

Tbx3

\section{E 16.5 primary sprout}

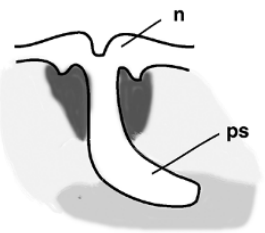

FGF10

LEF1

\section{PTHR1/PTHrP}

Genetic analysis of prenatal mammary gland development.

(a) Between embryonic days $(E) 11.5$ and 13.5 the mammary anlagen develops from a small placode contiguous with the ectoderm into a bud that invaginates the dermal mesenchyme (light gray). Rapid cell proliferation at the base of the bud leads to the formation of an elongated duct that grows toward the fat pad (intermediate gray shading) on embryonic day 16.5. The mammary mesenchyme (dark shading), which is induced by parathyroid hormone-related protein (PTHrP) signals emanating from the mammary epithelium, abuts the placode and bud and contributes to the formation of the nipple.

(b) The stages of arrest in mammary gland development caused by the different gene deletion mutants are indicated by bars. b, bud; ec, ectoderm; ep, epidermis; n, nipple; p, placode; ps, primary sprout; FGF, fobroblast growth factor.

\section{Molecular events}

In evolutionary terms the mammary gland is a rather young organ. It is thought to be derived from apocrine-like skin glands of synapsids, which probably served as a source of moisture for the parchment-shelled eggs and as a source of nutrients for the hatchlings [2]. The origin of the gland in close association with feathers and hair is still reflected on a molecular level. A number of genes are expressed in hair, whiskers and feathers as well as in the mammary gland, and deletion of some genes affects development of all the epidermal appendages. Another common feature of all skin appendages is the dependence on reciprocal signals between the epithelium and the mesenchyme (for a review, see $[3,4])$.

What are the signals that direct the commitment of a distinct set of ectoderm cells toward the appendage or, more specifically, the mammary epithelial fate? The regional and temporal expression patterns and the results of targeted gene deletion and overexpression studies have identified several signaling pathways that are active in the early stages of bud development and are required for development of the anlagen (Fig. 1b).
Fibroblast growth factor (FGF) signals play an important role in many sites of epithelial mesenchymal interactions and are also involved in mammary bud formation. In the absence of the FGF receptor FGFR2b or its ligand FGF10, all but the first inguinal mammary anlagen fail to develop [5]. Interestingly, in the receptor null mutant the bud is formed and regresses by apoptosis, while in FGF10-deficient embryos it is maintained but fails to undergo branching. While Fgfr2b is expressed in the mammary placodes from embryonic day 11 onward, the earliest expression of Fgf10 is detected on embryonic day 15.5 only. Expression of Fgf7 occurs at an earlier stage and is thought to compensate for the absence of FGF10. This probably explains the difference in the phenotype of the mutation of the receptor and the ligand. Transplantation of Fgf10 null epithelia demonstrates that the requirement for FGF10 extends into the postnatal period. Mammary ducts develop slower but do not seem to have any morphological defects, indicating that FGF10 regulates cell proliferation rather than ductal branching [5].

The first indication for an involvement of wnt signals came from deletion of the gene encoding the transcription factor Lef1 [6]. This member of the TCF/LEF family mediates extracellular wnt signals. It is expressed in mammary anlagen from embryonic day 11.5 onward. Mammary placodes are formed in its absence, but their development is arrested at the early bud stage. Among the many members of the wnt family, wnt6, wnt 10a and wnt10b start to be expressed in the surface ectoderm around embryonic day 11.25, preceding the appearance of mammary placodes. Interestingly, wnt 6 and $w n t 10 b$ are first expressed along a line that seems to define a border between the dorsal and the ventral body walls. Within about 36 hours the expression becomes restricted to the placodes [7].

This expression pattern suggests that formation of the placodes results from the migration of wnt-expressing cells along the milk line accompanied by enhanced expression in the cells that form the placode. In a line of mice that harbor a transgene that serves as a reporter for wnt activity on the transcriptional level (TOP-gal), regionally restricted wnt signals along the milk line have been confirmed independently (JJ Wysolmerski, personal communication, 2004). The importance of wnt signaling is further illustrated by the finding that expression of Dkk1 (Dickkopf), an inhibitor of wnt signals, in the mammary anlagen results in an absence of mammary buds [8].

A naturally occurring spontaneous mutation in the $T B X 3$ gene is the cause of human ulnar mammary syndrome, which manifests itself in abnormal forelimb and apocrine gland development [9]. Tbx3 encodes a T-box transcription factor that is expressed in the mammary bud 
and other sites of tissue interactions, such as the limb bud [10]. Mice with a targeted deletion of $T b \times 3$ fail to develop mammary glands and also display limb and yolk sac deficiencies [11]. This signal appears to act at a very early stage in mammary organogenesis as mammary buds and localized expression of $w n t 10 b$ and Lef1 are absent in Tbx3 knockout mice.

Parathyroid hormone-related protein (PTHrP), a small peptide initially identified as the cause of humoral hypercalemia of malignancies, is not only involved in the regulation of calcium homeostasis, but also mediates the formation of the primary mammary mesenchyme and nipple sheath. PTHrP is expressed in the mammary bud, and the receptor PTHR1 is expressed in the ventral dermal mesenchyme [12]. Ectopic expression of PTHrP by a keratin 14 promoter-driven transgene leads to an expansion of nipple skin and connective tissue over the entire belly, demonstrating that PTHrP produced in the epithelium induces a change in the differentiation of dermal fibroblasts [13]. Genetic confirmation of the absolute requirement of this signaling pathway for mammary gland development comes from gene deletion studies. Identical phenotypes, namely an arrest of mammary gland development before outgrowth of the primary sprout, occur upon targeted deletion of PTHrP or the receptor PTHR1 [14]. A loss-of-function mutation in the PTHR1 gene in humans causes Blomstrand chondrodysplasia, a rare, lethal form of dwarfism characterized by defects in endochondral bone formation and the absence of nipples and breasts [15].

In another instance, the combination of human and mouse genetics has shed light on a previously unidentified signal that affects mammary gland development. Mutations in ectodysplasin (Eda), a member of the tumor necrosis factor family, its receptor Edar and the Edar-binding death domain adaptor protein Edaradd have been associated with hypohidrotic ectodermal dysplasias, with malformation of hair, teeth and sweat and with malformation of exocrine glands. Expression of these molecules has not been studied in detail in the mammary gland but, in developing teeth and hair, Eda and Edar are first coexpressed in the simple ectodermal sheath before the morphological appearance of placodes $[16,17]$. Their expression patterns later become complementary; Eda is downregulated in the placodes but remains high in the adjacent ectoderm, and Edar expression persists in the placodes. Furthermore, the expression of Eda is induced by wnt via the Lef1 pathway. When Eda is ectopically expressed from the keratin 14 promoter, supernumorary nipples develop which are attached to a small ductal system along the presumptive milk line [18]. Ectodysplasin appears to mediate intraectodermal signals involved in epithelial patterning rather than mediating signals from one tissue to another.

\section{Conclusions}

These recent examples of the identification of novel signaling mechanisms that direct mammary gland development during the embryonic stage demonstrate a few interesting points.

Some of the findings were clearly serendipitous and have driven research into new directions. However, the generation of mouse models of mutations associated with defects in breast development in humans has taken a more directed approach. There are more syndromes such as the limb-mammary syndrome and the acro-dermatoungual-lacrimal-tooth syndrome, which have been mapped to the $p 63$ gene. The role of $p 63$ has not been thoroughly investigated in the context of mammary gland development [19]. Interestingly, deletion of the $p 63$ gene in mice leads to inhibition of skin differentiation and a complete absence of skin derivatives, as well as to craniofacial and limb deformities [20,21]. This indicates that $\mathrm{p} 63$ is critical for cell proliferation and/or differentiation in tissues that depend on epithelial mesenchymal interactions.

Second, none of the mutations so far identified are unique to the mammary gland and there is no indication that only one signal directs specification of the mammary epithelium. Yet each mutation appears to affect different appendages in distinct ways. This demonstrates that the signals most probably activate downstream genes in cellspecific contexts.

Finally some of the genes, such as $P T H r P$ and $T b x 3$, are upregulated in cancer. It remains to be determined whether other signaling pathways that regulate cell specification and proliferation, signaling between epithelium and mesenchyme, cell migration and ductal morphogenesis are also active in tumors. Understanding their role in normal development may also influence our thinking about regulatory processes in neoplastic tissues.

While wnt signals seem to be crucial in the initial stages of mammary development it is not yet clear whether the different pathways that are active during these stages are interconnected or independent of each other (Fig. 1b). Careful comparison and staging of the developmental arrests caused by the different mutants in conjunction with expression analyses of specific markers (such as the genes involved in wnt, FGF and Eda signaling) will be required for the development of a cohesive model of the genetic interactions among these pathways. Undoubtedly, more genes will be discovered that play a role in early mammary gland development and other ectoderm-derived organs. Our challenge in the future will be to understand these pathways, their interactions and the developmental programs they activate. 


\section{Competing interests}

None declared.

\section{References}

1. Veltmaat JM, Mailleux AA, Thiery JP, Bellusci S: Mouse embryonic mammogenesis as a model for the molecular regulation of pattern formation. Differentiation 2003, 71:1-17.

2. Oftedal OT: The mammary gland and its origin during synapsid evolution. J Mammary Gland Biol Neoplasia 2002, 7:225252.

3. Robinson GW, Karpf ABC, Kratochwil K: Regulation of mammary gland development by tissue interaction. J Mammary Gland Biol Neoplasia 1999, 4:9-19.

4. Hennighausen L, Robinson GW: Signaling pathways in mammary gland development. Dev Cell 2001, 1:467-475.

5. Mailleux AA, Spencer-Dene B, Dillon C, Ndiaye D, Savona-Baron C, Itoh N, Kato S, Dickson C, Thiery JP, Bellusci S: Role of FGF10/FGFR2b signaling during mammary gland development in the mouse embryo. Development 2002, 129:53-60.

6. van Genderen C, Okumura RM, Farinas I, Quo RG, Parslow TG, Bruhn L, Grosschedl R: Development of several organs that require inductive epithelial-mesenchymal interactions is impaired in LEF-1-deficient mice. Genes Dev 1994, 8:2691-2703.

7. Veltmaat JM, Van Veelen W, Thiery JP, Bellusci S: Identification of the mammary line in mouse by Wnt10b expression. Dev Dyn 2004, 229:349-356.

8. Andl T, Reddy ST, Gaddapara T, Millar SE: WNT signals are required for the initiation of hair follicle development. Dev Cell 2002, 2:643-653.

9. Bamshad M, Lin RC, Law DJ, Watkins WS, Krakowiak PA, Moore ME, Franceschini P, Lala R, Holmes LB, Gebuhr TC, Bruneau BG, Schinzel A, Seidman CE, Jorde LB: Mutations in human TBX3 alter limb, apocrine and genital development in ulnarmammary syndrome. Nat Genet 1997, 16:311-315.

10. Chapman DL, Garvey N, Hancock S, Alexiou M, Agulnik S, Gibson Brown JJ, Cebra-Thomas J, Bollag RJ, Silver LM, Papaioannou VE: Expression of the T-box family genes, Tbx1-Tbx5, during early mouse development. Dev Dyn 1996, 206:379-390.

11. Davenport TG, Jerome-Majewska LA, Papaioannou VE: Mammary gland, limb and yolk sac defects in mice lacking $T b \times 3$, the gene mutated in human ulnar mammary syndrome. Development 2003, 130:2263-2273.

12. Dunbar ME, Dann PR, Robinson GW, Hennighausen L, Zhang JP, Wysolmerski JJ: Parathyroid hormone-related protein signaling is necessary for sexual dimorphism during embryonic mammary gland development. Development 1999, 126:34853493.

13. Foley J, Dann P, Cosgrove J, Dreyer B, Rimm D, Dunbar ME, Philbrick W, Wysolmerski JJ: Parathyroid hormone-related protein maintains epithelial cell fate and triggers nipple skin differentiation during embryonic development. Development 2001, 128:513-525.

14. Wysolmerski JJ, Philbrick WM, Dunbar ME, Lanske B, Kronenberg $H$, Karaplis $A$, Broadus $A E$ : Rescue of the parathyroid hormonerelated protein knockout mouse demonstrates that parathyroid hormone-related protein is essential for mammary gland development. Development 1998, 125:1285-1294.

15. Wysolmerski JJ, Cormier S, Philbrick WM, Dann P, Zhang JP, Roume J, Delezoide AL, Silve C: Absence of functional type 1 parathyroid hormone (PTH)/PTH-related protein receptors in humans is associated with abnormal breast development and tooth impaction. J Clin Endocrinol Metab 2001, 86:1788-1794.

16. Laurikkala J, Mikkola M, Mustonen T, Aaberg T, Koppinen P, Pispa J, Nieminen P, Galceran J, Grosschedl R, Thesleff I: TNF signaling via the ligand-receptor pair ectodysplasin and edar controls the function of epithelial signaling centers and is regulated by Wnt and activin during tooth organogenesis. Dev Biol 2001, 229:443-455.

17. Laurikkala J, Pispa J, Jung HS, Nieminen P, Mikkola M, Wang X, Saarialho-Kere U, Galceran J, Grosschedl R, Thesleff I: Regulation of hair follicle development by the TNF signal dysplasin and its receptor Edar. Development 2003, 129:2541-2553.

18. Mustonen T, Pispa J, Mikkola ML, Pummila M, Kangas AT, Pakkasjarvi L, Jaatinen R, Thesleff I: Stimulation of ectodermal organ development by Ectodysplasin A1. Dev Biol 2003, 259:123-136.
19. van Bokhoven $H$, Hamel BCJ, Bamshad M, Sangiorgio E, Gurrierri $F$, Duijf PHG, Vanmolkot KRJ, van Beusekom E, ven Beersum SEC, Celli J, Merkx GFM, Tenconi R, Fryns JP, Verloes FA, Newbury-Ecob RA, Raas-Rotschild A, Majewski F, Beerner FA, Janecke A, Chitayat D, Crisponi G, Kayserili H, Yates JRW, Neri G, Brunner HG: p63 gene mutations in EEC syndrome, limbmammary syndrome, and isolated split hand-foot malformation suggest a genotype-phenotype correlation. Am J Hum Genet 2001, 69:481-492.

20. Mill AA, Zheng BH, Wang XJ, Vogel H, Roop DR, Bradley A: p63 is a p53 homologue for limb and epidermal morphogenesis. Nature 1999, 398:708-713.

21. Yang A, Schweitzer R, Sun DQ, Kadhad M, Walker N, Bronson RT, Tabin C, Sharpe A, Caput D, Crum C, McKeon F: p63 is essential for regenerative proliferation in limb, craniofacial and epithelial development. Nature 1999, 398:714-718.

\section{Correspondence}

Gertraud Robinson, Laboratory of Genetics and Physiology, NIDDK, NIH, Building 8, Room 101, Bethesda, MD 20892-0822, USA. Tel: +1 301496 5004; fax: +1 301480 7312; e-mail: traudl@nih.gov 